Ensino, Saúde e Ambiente - V9 (2), pp. 45-62, Ago. 2016

\title{
A ODONTOLOGIA COMO TEMA PARA O ENSINO DE QUÍMICA: ESTUDO DE POSSIBILIDADES POR MEIO DE MAPAS CONCEITUAIS
}

\section{DENTISTRY AS SUBJECT TO THE CHEMISTRY EDUCATION: OPPORTUNITIES STUDIES USING CONCEPTUAL MAPS}

\author{
Eluzir Pedrazzi Chacon ${ }^{1}$, Lucas Junqueira de Carvalho ${ }^{2}$, Carlos Magno Rocha Ribeiro ${ }^{3}$ \\ ${ }^{1}$ Universidade Federal Fluminense, Programa de Pós-Graduação em Ensino de Ciências da Natureza, \\ Departamento de Química Inorgânica - eluzir_pedrazzi@id.uff.br \\ ${ }^{2}$ Universidade Federal Fluminense, Licenciado em Química - junqueira2000@yahoo.com \\ ${ }^{3}$ Universidade Federal Fluminense, Programa de Pós-Graduação em Ensino de Ciências da Natureza, \\ Departamento de Química Orgânica - carlosmagnoribeiro@id.uff.br
}

\begin{abstract}
RESUMO
O presente artigo reporta uma análise sobre a articulação da Química com a Odontologia através de mapas conceituais. A metodologia utilizada neste trabalho se caracteriza como básica, qualitativa e exploratória. Através da pesquisa bibliográfica foram observados os conteúdos químicos relacionados à conservação dos dentes e a saúde bucal, bem como sua aplicação ao Ensino de Química. Além disso, o trabalho baseia-se nos Parâmetros Curriculares Nacionais e tem como referencial teórico a teoria da aprendizagem significativa de David Ausubel. Dentro do tema "A Odontologia e a Química" abordaram-se cinco subáreas: (a) a formação do dente, (b) a cárie e sua formação, (c) lesões no dente; (d) retirada da cárie e fechamento da cavidade e (e) a conservação dos dentes. Estudou-se ainda a correlação entre essas subáreas e o Ensino de Química através de mapas conceituais. Os resultados apontam que o professor em sua sala de aula pode utilizar tópicos relacionados à Odontologia para fazer uma contextualização e com isso motivar o ensino/aprendizagem da Química no Ensino Médio, pois o tema em questão é muito rico, permitindo uma ampla discussão e aprofundamento de conteúdos essenciais à formação discente.
\end{abstract}

Palavras-chave: odontologia, ensino de química, mapas conceituais.

\begin{abstract}
This paper reports an analysis of the relationship between Chemistry and Dentistry through conceptual maps. The methodological research used in this work is characterized as basic, qualitative and exploratory. Through literature were observed chemical content related to the conservation of the teeth and oral health as well as their application to the Chemistry Teaching. Also, the work is based on the National Curricular Parameters and its theoretical framework with the theory of meaningful learning of David Ausubel. The theme "Dentistry and Chemistry" is addressed to five sub-areas: (a) the formation of the tooth, (b) the dental caries and their formation, (c) in the tooth injuries; (D) removal of dental caries and cavity closure and (e) the preservation of teeth. It is also studied the correlation between the sub-areas and Chemistry Teaching through conceptual maps. The results showed that the teacher in your classroom can use topics related to dentistry to make a contextualization and thereby motivate the teaching/learning of chemistry in high school, because the issue at hand is very rich, allowing a comprehensive discussion and deepening essential content to student training.
\end{abstract}

Key words: dentistry, teaching of chemistry, concept maps 


\section{Ensino, Saúde e Ambiente - V9 (2), pp. 45-62, Ago. 2016}

\section{INTRODUÇÃO}

A preocupação do homem com a conservação dos dentes vem desde a antiguidade, pois a necessidade de se alimentar fez com que ele percebe-se que os dentes tinham um papel crucial para a mastigação e trituração do alimento, e que a sua ausência atrapalhava a ingestão de diferentes gêneros alimentícios. No entanto, apesar de perceber sua importância não era raro a sua perda, principalmente através da formação da cárie. Hoje, devido aos novos hábitos alimentares e comportamentais da sociedade, outros motivos podem ser apontados para a perda do dente como a atrição dental, que consiste no desgaste mecânico das estruturas dentais causado pelo contato dente com dente (superior com inferior) durante a mastigação; a erosão dentária que ocorre quando há perda de estrutura dental em conseqüência de ação química, devido a fatores intrínsicos e extrínsicos, e a abrasão, que é um processo onde há perda patológica de estrutura dental de maneira mecânica, como por exemplo, na escovação inadequada (AMARAL et al., 2012). O reconhecimento inicial desses problemas permite impedir a progressão da lesão e restauro do dente (CATELAN et al., 2010; SANTOS-DAROZ et al., 2007).

As substâncias orgânicas e inorgânicas presentes na saliva influem na bioquímica do dente, onde o pH se caracteriza como um importante balizador na ação enzimática para a sua deterioração (CUNHA-CRUZ et al., 2013). As questões biológicas e químicas que envolvem a saliva e o dente também são discutidas por Cury et al. (2002), que apontam a importância do flúor na proteção dental, o qual é usado na água e dentifrícios, que são meios eficazes para sua aplicação e abordam ainda a sua toxicidade. O controle dos problemas originais do biofilme dental depende de uma higiene bucal adequada, que pode ser realizada por meio mecânico, químico ou a associação de ambos (BOTTAN et al., 2010). Na sociedade contemporânea a estética bucal é um fator importante, por isso não somente as questões envolvidas na perda dos dentes causadas por cáries e outras doenças, mas também o seu clareamento tem sido muito enfatizado e estudado. Desde 1860 existem diversas técnicas que buscam formas de clareamento dental, sendo que inúmeras substâncias químicas tem sido usadas para esse fim, como, por exemplo, cloreto de cálcio, cloro, cloreto de alumínio, ácido oxálico, dióxido de enxofre, hipoclorito de sódio, ácido oxálico, perborato de sódio mais peróxido de hidrogênio a $30 \%$ associado a uma fonte de calor, 5 partes de peróxido 


\section{Ensino, Saúde e Ambiente - V9 (2), pp. 45-62, Ago. 2016}

de hidrogênio a 30\% mais 1 parte de éter associado a uma fonte de calor para acelerar a reação de liberação de oxigênio, e a utilização de peróxido de carbamida a 10\% e mais recentemente, nas concentrações de $35 \%$ a $37 \%$ (SOSSAI, VERDINELLI e BASSEGIO, 2011).

Pode-se observar que o desenvolvimento da odontologia trouxe consigo a valorização dos aspectos de promoção e prevenção da saúde, além da melhoria do restauro, tratamento de doenças e questões estéticas relativas aos dentes, levando com isso a uma melhoria da saúde bucal, em detrimento aos aspectos curativos e mutiladores praticados tempos atrás.

Levantamentos epidemiológicos no Brasil em 1986, 1996 e 2003 a respeito da saúde bucal mostraram uma melhoria no índice que mede os dentes cariados, perdidos e obturados (CPOD) de crianças de doze anos, uma vez que diminuiu de 6,65 em 1986 para 2,78 em 2003. Entretanto, o índice CPOD médio das pessoas entre 35 a 44 anos em 2003 era de 20, sendo 65,7\% composto por dentes perdidos. Deste modo, observa-se que em relação a adultos e idosos não houve o mesmo perfil de melhoria na saúde bucal, quando comparados com as crianças, e segundo Saliba et al. (2010) isso se deve a anos de práticas odontológicas restritivas, curativistas e mutiladoras. A perda dos dentes ainda é aceita por muitos como natural e normal com o avançar da idade, apesar de documentos, mesmo que antigos, mostrarem os prejuízos de ordem estética, funcional e psicológica que a falta dos dentes pode acarretar na qualidade de vida e no comprometimento do convívio social. Nos últimos anos, pode-se observar uma crescente preocupação governamental com a saúde bucal da população brasileira, o que pode ser notado no trabalho de Gigante e Guimarães (2013), o qual mostra a trajetória dos projetos públicos em saúde bucal no Brasil, desde a implantação do Sistema Único de Saúde (SUS) na Constituição de 1988, e os resultados obtidos até o momento. Os dados utilizados na pesquisa foram coletados de periódicos, artigos de revistas e nas bases de dados do Scielo, Google e fontes governamentais. Os autores citam o Programa de Avaliação da Saúde Bucal em 2003 (Projeto SB Brasil 2003), o Projeto Brasil Sorridente lançado em 2004 pelo Ministério da Saúde, com a participação de diversas faculdades e conselhos de Odontologia, além de profissionais da área ligados às universidades, e o Projeto SB Brasil 2010. Além disso, observaram principalmente que o modelo inicial de assistência à saúde bucal não utilizava de forma racional os 


\section{Ensino, Saúde e Ambiente - V9 (2), pp. 45-62, Ago. 2016}

recursos tecnológicos e de prática hospitalocêntrica e, que posteriormente passou a valorizar a atenção básica à saúde.

Acredita-se que estes projetos são extremamente importantes, mas, no entanto, há a necessidade de ações mais contundentes, principalmente nas escolas, buscando atingir crianças, adolescentes e jovens no entendimento da importância da saúde bucal para a sua vida. Assim, algumas questões podem ser levantadas, tais como: A saúde bucal é discutida nas salas de aula? O professor está preparado para trabalhar este tema com seus alunos? O livro didático aborda este assunto?

Marinho e Silva (2013) analisaram livros, artigos, teses, entre outras fontes, procurando problematizar três pontos referentes à questão da saúde bucal: diferenciar o entendimento de educação em saúde de outras designações (saúde escolar, ensino de saúde, educação para a saúde e promoção da saúde); traçar um apanhado histórico sobre a forma de estruturação da educação em saúde na escola brasileira; compreender as possibilidades e barreiras encontradas na concretização da educação em saúde na escola. Os autores observaram que por ter um caráter multifacetado, o conceito de educação em saúde necessita ser problematizado, para se buscar compreensões dos fenômenos referentes a esse tema e também, que desde a inserção do tema saúde nas escolas, é marcante a mudança comportamental. No entanto, apontam que dentre os fatores que limitam o trabalho docente, está a formação para trabalhar com esta questão e a falta de diálogo com profissionais da área de saúde. Ainda segundo os autores,

[...] para superar esses empecilhos seja necessários cursos de aperfeiçoamento para os professores, em relação à temática da educação em saúde, bem como um trabalho mais sistematizado entre educadores e profissionais da área da saúde (MARINHO e SILVA, 2013, p. 36).

Para saber o quanto a educação em saúde pode ser um importante meio para favorecer que uma pessoa adquira autonomia sobre sua saúde e prevenção a doenças, Mialhe e Silva (2011) indagaram a 67 alunos de um curso de odontologia, o que entendiam por educação em saúde. Das respostas obtidas nesta pesquisa concluíram que:

O conceito de educação em saúde dos acadêmicos está fortemente ligado ao conceito positivista de ensinamento, instrução e prevenção de doenças, pautados na ideia de que a falta de informações dos indivíduos é que os induz a não exercerem práticas saudáveis em saúde, sendo função do profissional educar as pessoas neste sentido e que existe a necessidade de estratégias de ensino-aprendizagem voltadas a transformar a representação da educação em saúde por parte dos acadêmicos (MIALHE e SILVA, 2011, p. 1558). 


\section{Ensino, Saúde e Ambiente - V9 (2), pp. 45-62, Ago. 2016}

Tanaka (2006) avaliou 251 materiais didáticos de 40 escolas públicas e privadas de Araçatuba-SP sobre a existência e abrangência de informações referentes à saúde bucal, tendo em vista que a educação e a saúde são duas ciências de grande importância para o desenvolvimento humano. Observou-se que apenas 25 dos livros de abordavam esse tema, e em geral, se apresentava de maneira fragmentada. Dentre as temáticas abordadas observam-se: a) relação saúde geral/saúde bucal; b) importância dos dentes/saúde bucal; c) higiene dental; d) instrumentos de higiene dental; e) visitas ao dentista; f) dieta; g) cárie; h) tipos de dentes; i) tipos de dentição e j) uso do flúor. Entretanto, observa-se que a higiene dental seguida pela formação da cárie são os temas mais abordados, enquanto os menos comentados são a relação entre saúde geral e bucal, e o uso do flúor.

Visando desenvolver estratégias de ensino-aprendizagem para a educação em saúde, em especial a saúde bucal, aliada ao ensino de Química, diversos trabalhos têm sido apresentados. Para auxiliar o professor na preparação de atividades didáticas para o ensino de Química articulando o tema saúde bucal, Souza (2013) elaborou um experimento simples para discutir a importância das forças de coesão entre as moléculas de água e substâncias químicas dos dentifrícios (pasta de dente), facilitando a penetração da água nos espaços entre eles. Já Silva et al. (2001) abordam aspectos da química dos dentifrícios, através da discussão e apresentação das substâncias que fazem parte de sua composição química, função na limpeza e prevenção das cáries usando reações químicas que demonstram esse processo, além de introduzir o tema restaurações acrílicas e com amálgamas. A discussão sobre colóides, seus tipos, suas estabilidades e sua importância no cotidiano e em diferentes aplicações tecnológicas, focalizando aspectos importantes da interface ciência/sociedade e sua relação com pasta de dentes, é apresentada por Junior e Varanda (1999).

Field`s et al. (2010) consideram que a falta de metodologias que pregam a contextualização no ensino de Química podem ser um dos motivos da rejeição de alguns conteúdos pelos alunos. No entanto, observa-se que o uso de temas geradores em sala de aula pode motivar o ensino e o aprendizado de Química, muitas vezes a curiosidade é aguçada ou o interesse sobre uma dada questão é despertado sem perder o foco da disciplina. Acreditando nessa ideia, os autores propõem aulas com o tema "cáries e dentifrícios" como propulsor para o conteúdo "equilíbrio químico". 


\section{Ensino, Saúde e Ambiente - V9 (2), pp. 45-62, Ago. 2016}

Como foi possível observar, a Química está diretamente ligada à saúde bucal, através da atuação de substâncias orgânicas e inorgânicas existentes na saliva e o desenrolar de suas ações, via reações químicas ou, pelos diversos produtos químicos que têm sido usados ao longo da história visando à profilaxia e cura de doenças bucais. Deste modo, a escolha deste tema vem trazer para o aluno não só o contexto da conservação dos dentes e sua relação com a Química, mas traz à tona aspectos relativos à higiene bucal que são imprescindíveis para a saúde do homem. Esta articulação pode facilitar a compreensão de que a Química está presente em nosso cotidiano, quebrandose o estigma de que esta é uma ciência abstrata que exige muita memorização e pouco utilizada fora dos muros da escola.

Assim, tendo em vista a importância deste tema para a saúde pública e a presença de processos e produtos químicos articulando a Química com a Odontologia, achou-se conveniente fazer um estudo sobre a relação de conteúdos químicos com a odontologia, utilizando mapas conceituais como ferramenta para mostrar estas articulações.

Os mapas conceituais são ferramentas interessantes para o ensino e avaliação da aprendizagem uma vez que podem enfatizar o sentido de unidade, articulação, subordinação e hierarquização dos conhecimentos sobre determinado tema, possibilitando, ao professor e aluno perceberem as dificuldades na aprendizagem e favorecer o desenvolvimento de suas habilidades e competências. Além disso, facilitam ao educador fazer uma avaliação formativa do estudante (PACHECO e DAMASIO, 2009). Um mapa conceitual é também um instrumento de elaboração de aulas, cursos, palestras, dentre outras atividades, pois possibilita uma articulação e hierarquização dos conceitos a serem abordados nesse tipo de ação educacional.

Deve-se ressaltar que esta pesquisa fundamentou-se na proposta dos Parâmetros Curriculares Nacionais para o Ensino Médio (PCNEM) que diz que é necessário quebrar o paradigma de que o estudo da Química é uma simples memorização de nomes, fórmulas e conhecimentos como fragmentos desligados da realidade dos alunos, já que esta pode ser um instrumento da formação humana ampliando os horizontes culturais e a o exercício da cidadania (BRASIL, 2006) e na teoria da aprendizagem significativa de David Ausubel, a qual valoriza a vivência do educando. Segundo Ausubel, para que haja uma aprendizagem significativa as novas informações devem ser relacionadas a conceitos relevantes e inclusivos contidos na 


\section{Ensino, Saúde e Ambiente - V9 (2), pp. 45-62, Ago. 2016}

estrutura cognitiva do ser que aprende (MOREIRA, 2011), neste caso, os fatos relacionados à odontologia podem servir como pontes cognitivas, proporcionando uma interação entre os novos conhecimentos e aqueles que o educando apresenta em sua estrutura cognitiva, fruto de sua experiência de vida.

Assim, este trabalho visa reportar um estudo realizado sobre a relação da Química com a Odontologia, e mostrar através de mapas conceituais as possibilidades do uso deste tema na sala de aula. O estudo foi dividido em cinco (5) subáreas, intituladas: (a) a formação do dente; (b) a cárie e sua formação; (c) lesões no dente; (d) retirada da cárie e fechamento da cavidade e (e) a conservação dos dentes. Dentro de cada uma destas subáreas são observados os conteúdos químicos que podem ser estudados nas salas de aula do Ensino Médio, os quais são explicitados através de mapas conceituais.

\section{PERCURSO METODOLÓGICO}

A pesquisa realizada caracteriza-se como qualitativa, pois segundo Neves (1996, p.1), ela busca a "obtenção de dados descritivos mediante o contato direto e interativo do pesquisador com a situação objeto de estudo"; é básica, pois para Silveira e Córdova (2009, p.34) “objetiva gerar conhecimentos novos, úteis para o avanço da Ciência, sem aplicação prática prevista" e exploratória, pois "visa proporcionar uma visão geral acerca de determinado fato" (RAUPP e BEUREN, 2006, p.80). A metodologia aplicada neste trabalho constou das seguintes atividades:

1. Elaboração de um diagrama $\mathrm{V}$, buscando resumir os objetivos da pesquisa, e sistematizar a maneira de pensar e agir em busca das articulações entre os conteúdos químicos e o tema gerador;

2. Pesquisa bibliográfica sobre o tema Odontologia. Nesse caso seria possível perceber conceitos envolvidos na "Química do dente";

3. Estudo da viabilidade da utilização do tema "A Odontologia e a Química" no Ensino de Química através do levantamento de assuntos relacionados à Odontologia que podem ser articulados com os conteúdos químicos ministrados no Ensino Médio;

4. Criação de mapas conceituais;

5. Análise final sobre as possibilidades do uso do tema a partir dos mapas conceituais. 


\section{RESULTADOS E DISCUSSÃO}

Para nortear a pesquisa sobre a articulação da odontologia com a Química, foi elaborado o diagrama V mostrado na Figura 1, que é um instrumento heurístico proposto por Gowin para a análise do processo de produção do conhecimento (MOREIRA, 2011). A partir dele podemos sintetizar toda a pesquisa realizada.

Figura 1: Diagrama V elaborado para nortear a pesquisa

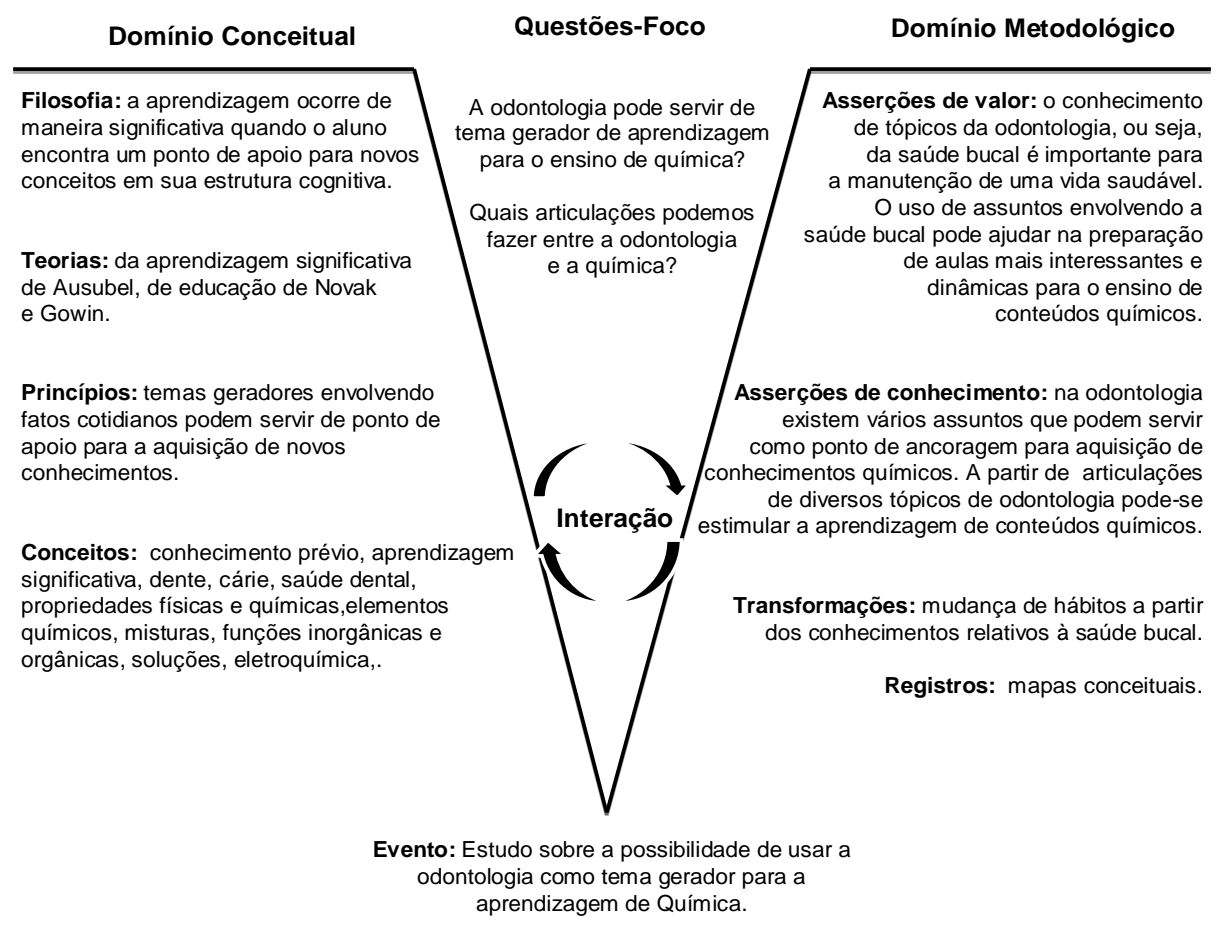

Fonte: Autor 1.

Pode-se observar no diagrama V elaborado, que duas questões nortearam este trabalho. São elas: A odontologia pode servir de tema gerador de aprendizagem para o ensino de Química? Quais as articulações podemos fazer entre a odontologia e a Química? Buscando responder estas questões foi realizada uma extensa pesquisa bibliográfica, a qual mostrou que vários tópicos relativos à saúde bucal podem ser utilizados no ensino de conteúdos químicos, os quais podem ser apontados através de mapas conceituais. Dentro do domínio conceitual, pode-se observar que a teoria da aprendizagem significativa de Ausubel foi utilizada como referencial teórico, enquanto no domínio metodológico, observa-se que ao se trabalhar a saúde bucal como um tema gerador em uma sala de aula o professor pode preparar aulas mais interessantes e 
articuladas ao cotidiano discentes, os quais podem compreender com mais facilidade a importância de certos conceitos químicos na manutenção de uma vida mais saudável.

A partir da pesquisa bibliográfica realizada observaram-se quais o conteúdos químicos poderiam ser articulados a Odontologia. Para apontar estas articulações foram utilizados mapas conceituais, os quais se mostraram excelentes ferramentas para sintetizar os resultados encontrados na pesquisa. A sua análise revela rapidamente quais os tópicos da odontologia podem ser utilizados na contextualização de conteúdos químicos possíveis de serem abordados em sala de aula.

A seguir serão mostrados os mapas conceituais elaborados para cada subárea da odontologia.

\section{(a) FORMAÇÃO DO DENTE}

A odontogênese é o processo de desenvolvimento do dente, que começa na sexta semana de gestação. $\mathrm{Na}$ composição química do dente aparecem vários elementos químicos, sendo o cálcio, o fósforo e o magnésio os mais importantes. O cálcio e o fósforo estão envolvidos na formação dos dentes devido a sua decomposição sobre a matriz orgânica, e são de fundamental importância na formação do dente, pois a falta desses minerais afeta a composição do esmalte, gerando dentes com imperfeições e pouca resistência ao esforço mastigatório (VASUDEVAN et al., 2011). Outros compostos e elementos encontrados nos tecidos dentários são o carbonato, o sódio e o cloro. $\mathrm{O}$ esmalte que envolve o dente tem como principal componente a hidroxiapatita, $\mathrm{Ca}_{5}\left(\mathrm{PO}_{4}\right)_{3} \mathrm{OH}$, que é muito pouco solúvel em água e o mais duro tecido calcificado do corpo humano (SILVA et al., 2001). A Figura 2 mostra um mapa conceitual que exibe a articulação entre a odontogênese e a Química. 
Figura 2: Mapa conceitual sobre a relação da odontogênese e a Química

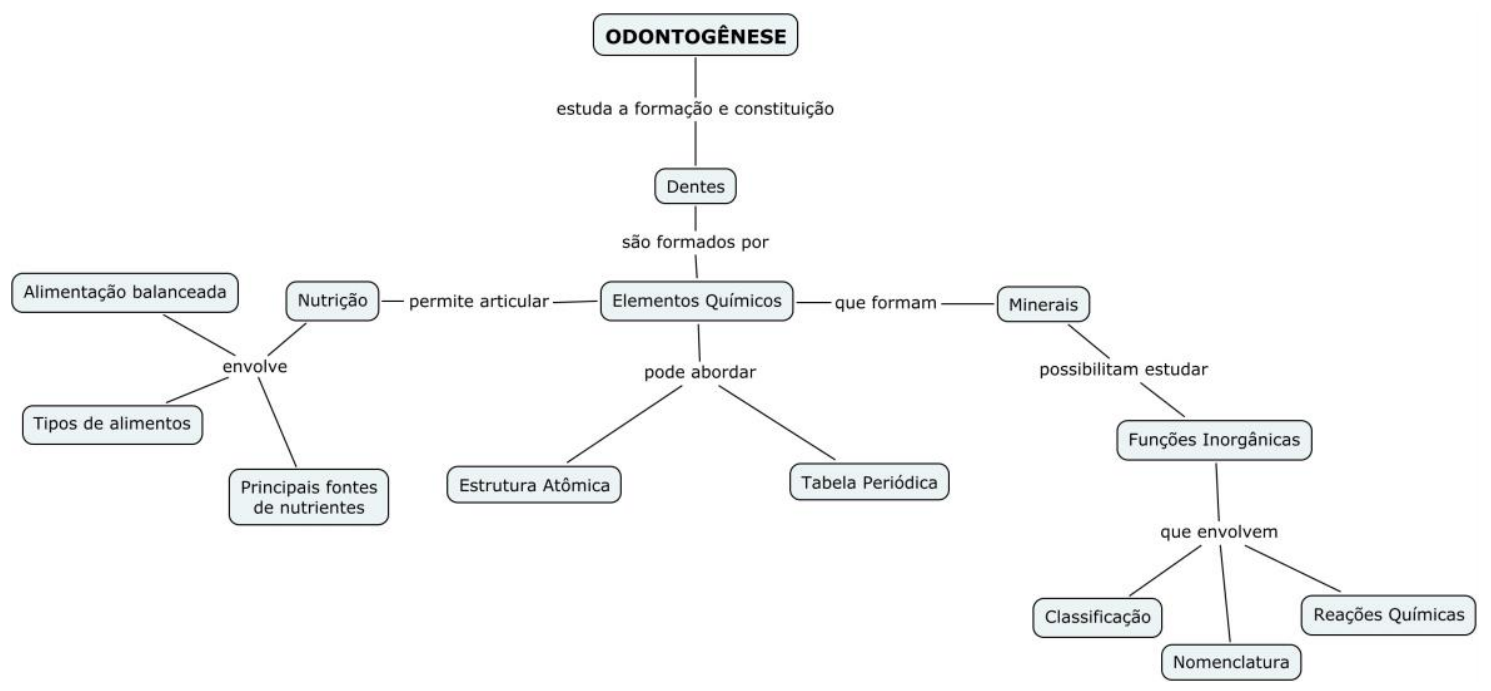

Fonte: Autores 1 e 2.

A formação do dente envolve vários elementos e substâncias químicas, e permite ao professor articular conteúdos químicos como Estrutura Atômica, Tabela Periódica e Funções Inorgânicas, além disso, pode-se trabalhar com a Biologia quando mostra a importância de uma alimentação nutritiva e balanceada para a formação de dentes saudáveis.

\section{(b) A CÁRIE E A SUA FORMAÇÃO}

$\mathrm{O}$ esmalte que envolve o dente tem como principal componente a hidroxiapatita, $\mathrm{Ca}_{5}\left(\mathrm{PO}_{4}\right)_{3} \mathrm{OH}$, que em um processo chamado desmineralização pode se dissolver. O processo inverso é chamado de mineralização. Assim, a reação de mineralização e desmineralização abaixo está em equilíbrio:

$$
\mathrm{Ca}_{5}\left(\mathrm{PO}_{4}\right)_{3} \mathrm{OH}_{(\mathrm{s})} \rightleftharpoons 5 \mathrm{Ca}_{(\mathrm{aq})}^{2+}+3 \mathrm{PO}_{4}{ }_{(\mathrm{aq})}+\mathrm{OH}_{(\mathrm{aq})}^{-}
$$

O equilíbrio químico está diretamente ligado à formação da cárie.

Segundo Lima (2007, p.121) o conceito de cárie dentária aceito universalmente é "doença multifatorial, infecciosa, transmissível e dieta dependente, que produz uma desmineralização das estruturas dentárias". Este conceito leva em consideração a suscetibilidade do indivíduo e do dente, a ação de microorganismos e a dieta determinada pela presença de carboidratos, principalmente a sacarose. Os microorganismos presentes na boca utilizam a sacarose como substrato para sintetizar polissacarídeos extracelulares importantes na formação da placa bacteriana e na 
produção de ácidos orgânicos que atuam nas reações de desmineralização do esmalte. $O$ autor ao longo do artigo tece várias considerações a respeito do conceito de cárie, se ela é uma doença ou não e dos vários fatores que influenciam na sua formação, e no final do seu estudo conclui que a "cárie é uma lesão do esmalte dentário provocada por um desequilíbrio químico local” (LIMA, 2007, p. 127-128). A Figura 3 mostra a formação da cárie.

Figura 3: Mapa conceitual sobre a formação da cárie

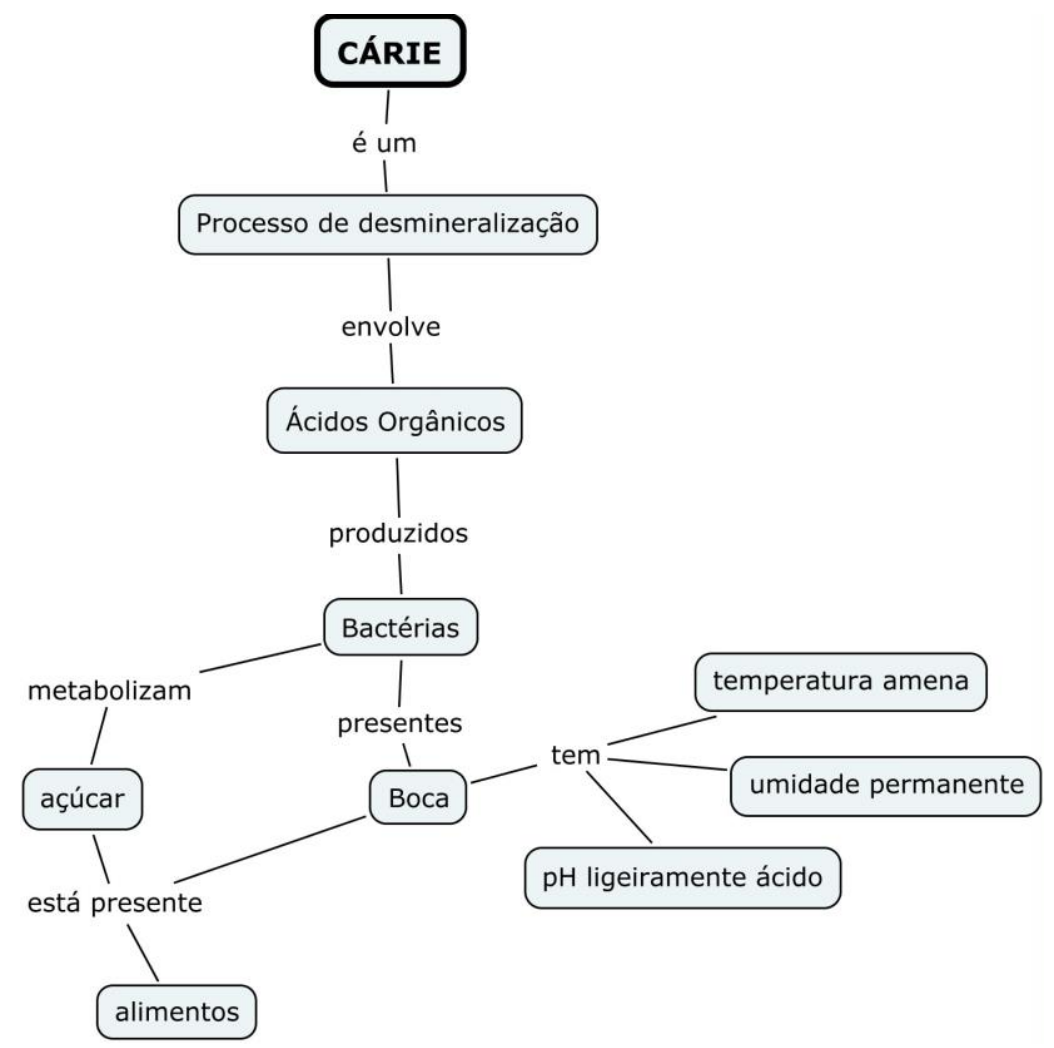

Fonte: Autores 1 e 2.

O processo de formação da cárie permite trabalhar o equilíbrio químico nas salas de aula do Ensino Médio. Pode-se verificar o Princípio de Lê Chatelier e observar o efeito do flúor na redução de cárie. O principio ativo do processo é o fluoreto, que interferirá no equilíbrio mineralização/desmineralização. Na presença no íon fluoreto, observa-se o seguinte equilíbrio:

$$
5 \mathrm{Ca}^{2+}{ }_{(\mathrm{aq})}+3 \mathrm{PO}_{4}{ }^{3-}{ }_{(\mathrm{aq})}+\mathrm{F}^{-}{ }_{(\mathrm{aq})} \rightleftarrows \mathrm{Ca}_{5}\left(\mathrm{PO}_{4}\right)_{3} \mathrm{~F}_{(\mathrm{s})}
$$

A fluoroapatita é menos solúvel que a hidroxiapatita e devido a isto protegerá o dente de novas cáries. Assim, pode-se, por exemplo, estudar o conteúdo de equilíbrio de solubilidade. 


\section{Ensino, Saúde e Ambiente - V9 (2), pp. 45-62, Ago. 2016}

\section{(c) LESÕES NO DENTE}

Segundo Amaral et al (2012), uma lesão não cariosa no dente deve-se ao seu envelhecimento, podendo ser patológico, caso esse processo fisiológico cause algum grau de destruição, criando desde problemas estéticos a funcionais. Os desgastes por atrição, abrasão, abfração e erosão muitas vezes podem estar associados a uma combinação de vários fatores, como por exemplo, o uso abusivo de drogas e substâncias ácidas, fatores ambientais e refluxo gastroesofágico.

A abrasão é um processo de desmineralização lento, gradual e progressiva estando relacionado a hábitos das pessoas. A atrição é o desgaste fisiológico da superfície do dente proveniente do contato entre eles como, por exemplo, no processo da mastigação, já a abfração é causada por forças tencionais e compreensivas secundárias pela flexão dos dentes.

A erosão por sua vez é a perda progressiva da estrutura do dente causada por processos químicos não bacterianos. Nesse caso estão envolvidos ácidos contidos em bebidas como, por exemplo, sucos de frutas, vinhos, desportivas, refrigerantes e em alimentos, tais como ácido lático, cítrico e málico, dentre outros. Essas substâncias possuem um $\mathrm{pH}$ que vai até o valor de 5,5 que podem levar a uma desmineralização do esmalte, já para a dentina, um valor de $\mathrm{pH}$ abaixo de 6,5 e outros fatores como a acidez titulada, quantidade de cálcio, fosfato e fluoretos em diversos produtos do cotidiano, leva a mesma nocividade. A quantidade de cálcio presente na saliva pode atenuar a ação dos ácidos, entretanto a acidez constante dificulta a remineralização do dente.

A queda do $\mathrm{pH}$ pode causar uma perda da apatita do esmalte do dente, podendo causar até uma dissolução de até quatro vezes da hidroxiapatita. Ressalta-se que a concentração de hidroxila é inversamente proporcional à concentração de íons hidrogênio e a concentração dos fosfatos dependem do pH. Assim, valores entre 5,2 e 5,5 podem ser críticos para a formação de lesões. O uso de clareadores, medicamentos, por exemplo, antidepressivos, anti-hipertivos e anticonvulsivantes, vitaminas de uso contínuo e drogas ilícitas podem facilitar as lesões dentárias não bacterianas. Do mesmo modo, dentifrícios ácidos não fluoretados podem favorecê-las (AMARAL et al., 2012).

Como é possível observar, a Química está envolvida diretamente nesse processo. Assim, em sala de aula é possível discutir, por exemplo, as classes de 
substâncias orgânicas e inorgânicas, bem como as funções orgânicas contidas em cada uma, que podem favorecer a formação de lesões ou contribuir para sua diminuição. $\mathrm{O}$ uso de rótulos de medicamentos e experimentos envolvendo bebidas são alguns exemplos que podem ser usados no processo de ensino/aprendizagem da Química, tornando-a interessante, contextualizada e próxima do dia a dia das pessoas de forma cidadã e responsável.

O mapa conceitual apresentado na Figura 4 mostra a formação de lesões do dente, considerando fatores bacterianos e não bacterianos e alguns de seus desdobramentos em possíveis conceitos químicos do processo de perda do dente.

Figura 4: Mapa conceitual sobre as lesões no dente

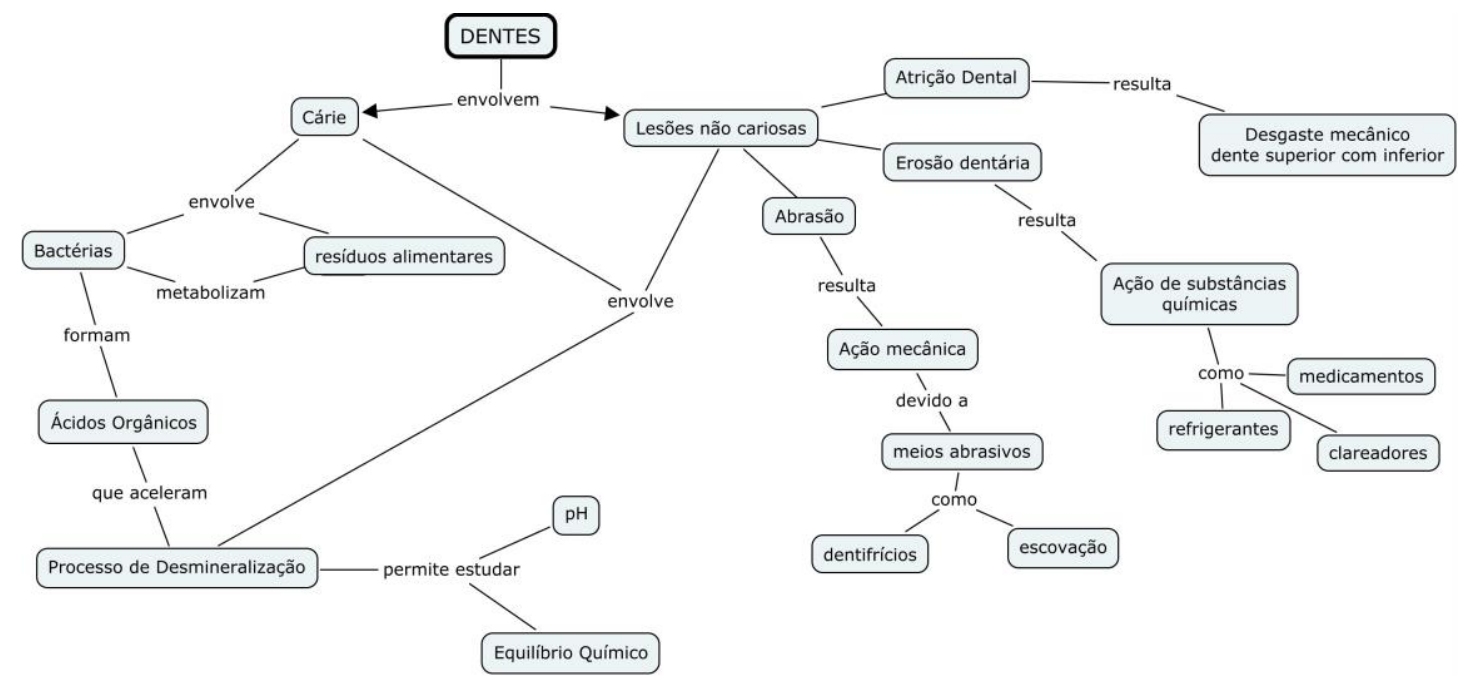

Fonte: Autor 1.

\section{(d) RETIRADA DA CÁRIE E FECHAMENTO DA CAVIDADE}

Dentre os procedimentos de retirada da cárie podemos citar aqueles que usam substâncias químicas, o laser e a ação mecânica pelo uso de brocas (GUEDES et al., 2006). Nesse último caso ocorre o atrito com a parte afetada do dente. Nas três situações para a retirada do problema dental por essas técnicas ocorre a formação de uma cavidade no dente que deve ser fechada para dificultar a formação de nova cárie na medida em que se protege o dente. O fechamento da cavidade provocada pela retirada da cárie, isto é, a sua restauração, pode ser realizada pelo uso de resina ou de amálgama. As resinas normalmente usadas são polímeros como o polimetracrilato de metila, o qual é sintetizado pela reação rápida entre o monômero metacrilato de metila com o uso de 
catalisadores como peróxidos e luz ultravioleta. Já a amálgama é preparada pela mistura de mercúrio e um metal ou ligas, compostas por prata, estanho, cobre ou zinco.

Essa gama de substâncias e procedimentos envolvidos na retirada da cárie e na sua restauração permite que seja discutido em sala de aula uma série conteúdos de Química que são abordados no Ensino Médio, como pode ser observado no mapa conceitual da Figura 5.

Figura 5: Mapa conceitual sobre a retirada da cárie e fechamento da cavidade

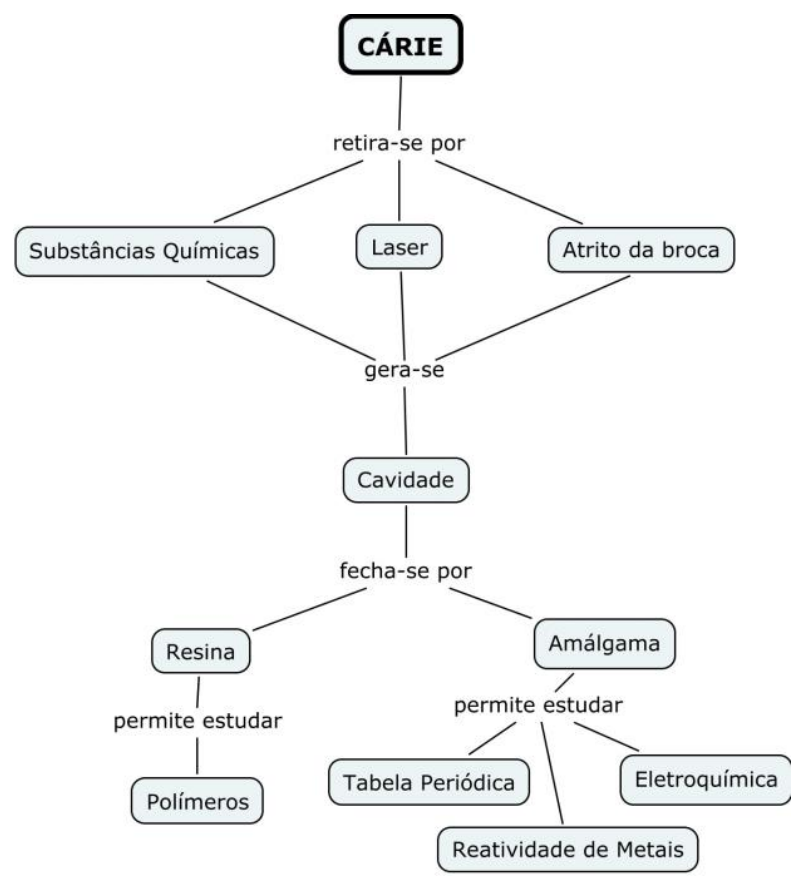

Fonte: Autor 1.

\section{(e) CONSERVAÇÃO DOS DENTES}

A conservação dos dentes é um dos momentos mais importantes para a saúde bucal, tendo em vista que o cuidado com eles permite sua preservação até a idade adulta dificultando a perda permanente e causando desconforto na terceira idade. Além disso, a prevenção da formação de cáries, por exemplo, diminuiria gastos governamentais para futuros reparos pelas clínicas e hospitais do sistema de saúde brasileiro. Desse modo, além de discussões sobre saúde pública, pode ser abordado em sala de aula do Ensino Médio a utilização de escovas e fios dentais, dentifrícios e enxaguatórios bucais. As escovas e fios dentais são feitas de polímeros, enquanto, os dentifrícios e enxaguatórios são constituídos de diversas classes de substâncias como aglutinantes, aromatizantes, conservantes, espumantes, dentre outros. Na elaboração do mapa conceitual consideraram-se essas questões (Figura 6), o qual mostra conceitos químicos 
importantes que podem ser discutidos para facilitar e contextualizar a importância da conservação dos dentes.

Figura 6: Mapa conceitual sobre a conservação dos dentes

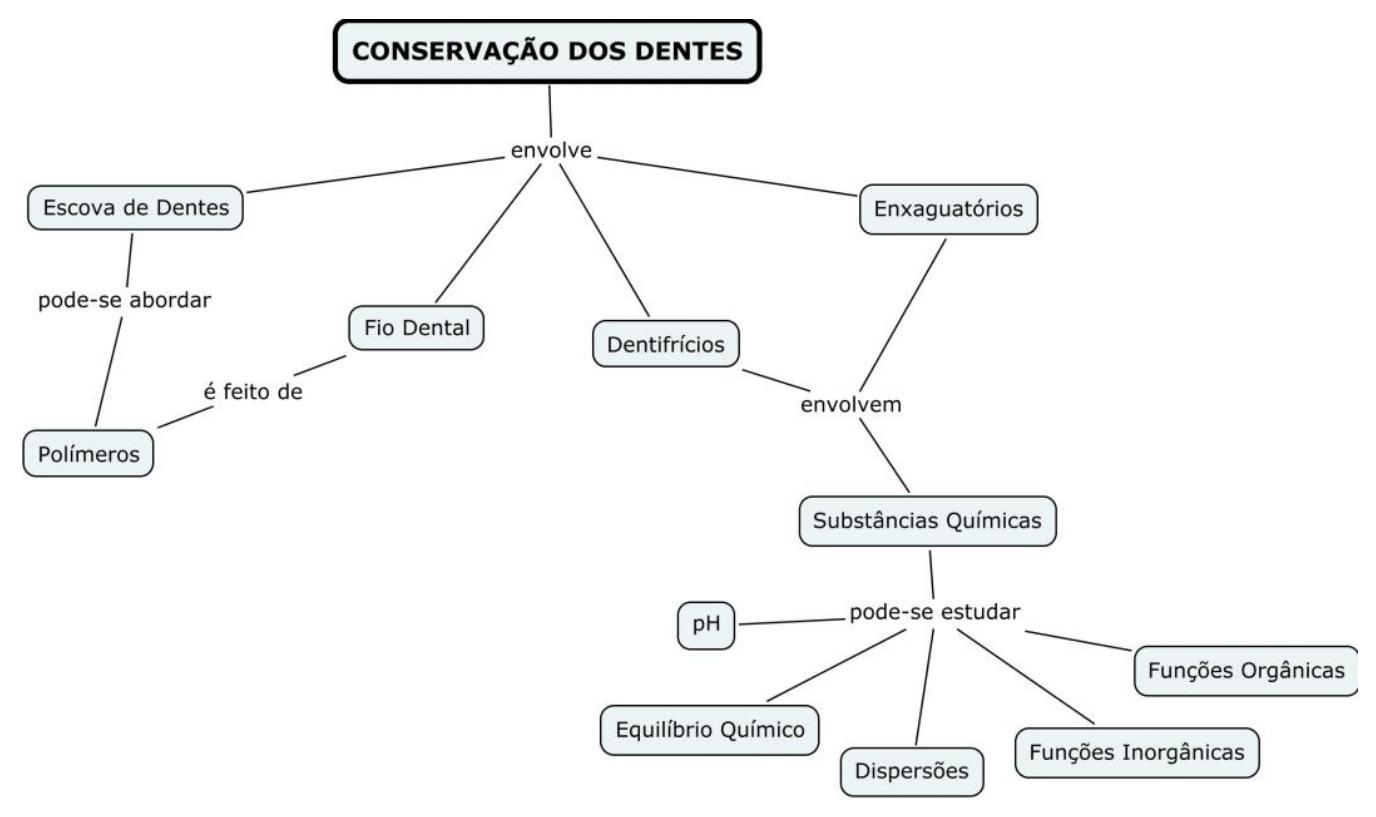

Fonte: Autores 1 e 2.

\section{CONSIDERAÇÕES FINAIS}

Este trabalho não teve a pretensão de fazer um estudo aprofundado sobre a Odontologia, mas observar como utilizar os diversos assuntos relevantes em relação à saúde bucal para instigar os educandos e criar pontes cognitivas para a aprendizagem de conteúdos químicos.

Portanto, procurou-se estudar a viabilidade de correlacionar a Odontologia com a Química, e constatou-se que é possível utilizar esse tema como agente motivador para salas de aulas em escolas do Ensino Médio, que é muito rico e pode ser explorado por professores de Química de modo a contextualizar conteúdos e fazer uma articulação com outras Ciências, como por exemplo, a Biologia.

Os mapas conceituais mostraram-se ferramentas poderosas para auxiliar o professor a definir quais os conteúdos químicos a serem ministrados dentro de uma parte específica da Odontologia, ajudando a melhorar a visualização das relações entre os conceitos e entre a Odontologia e a Química.

Deve-se ressaltar que o objetivo principal deste trabalho foi alcançado e que se espera que a pesquisa bibliografia realizada conjugada com os mapas conceituais 


$$
\text { Ensino, Saúde e Ambiente - V9 (2), pp. 45-62, Ago. } 2016
$$

mostrem as articulações entre a Odontologia e a Química, contribuindo para que outros professores utilizem este tema em suas salas de aula, buscando aprendizagens significativas.

\section{REFERÊNCIAS BIBLIOGRÁFICAS}

AMARAL, S. M.; ABAD, E. C.; MAIA, K. D.; WEYNE, S.; OLIVEIRA, M. P. R. P. B.; TUÑAS, I. T. C. Lesões não cariosas: o desafio do diagnóstico multidisciplinar. Arquivos Internacionais Otorrinolaringol. v. 16, n. 1, p. 96-102, 2012.

BOTTAN, E.; CAMPOS, L.; ODEBRECHT, C. M. R.; SILVEIRA, E. G.; SCHMITT, P.; ARAÚJO, S. M. Critérios adotados para a escolha da escova dental: estudo com consumidores de Florianópolis, Santa Catarina (Brasil). Revista Sul-Brasileira de Odontologia. v. 7, n. 2, p. 173-181, 2010.

BRASIL. Secretaria de Educação Média e Tecnológica - Ministério da Educação e Cultura. Parâmetros Curriculares Nacionais para o Ensino Médio: Ciências da Natureza, Matemática e suas Tecnologias. Brasília: MEC/SEMTEC. 2006. Disponível em: $<$ http://portal.mec.gov.br/seb/arquivos/pdf/book_volume_02_internet.pdf $>$. Acessado em: 10/06/2016.

CATELAN, A.; GUEDES, A. P. A.; SANTOS, P. H. Erosão dental e suas implicações sobre a saúde bucal. Revista da Faculdade de Odontologia, Universidade de Passo Fundo. v. 15, n. 1, p. 83-86, 2010.

CUNHA-CRUZ, J.; SCOTT, J.; ROTHEN, M.; MANCL, L.; LAWHORN, T.; BROSSEL, K.; SALIVARY, J. B. Characteristics and dental caries evidence from general dental practices. The Journal of the American Dental Association. v. 144, n. 5, p. 31-40, 2013.

CURY, J. A. Uso do flúor e controle da cárie como doença. Em: BARATIERI, L.N.; MONTEIRO JUNIOR, S.; ANDRADA, M. A. C.; VIEIRA, L. C. C.; RITTER, A. V.; CARDOSO, A. C. Odontologia restauradora: fundamentos e possibilidades. Säo Paulo, Santos, 2015.

FIELD`S, K. A. P.; OLIVEIRA, A. R. P.; QUINTINO, C. P.; CORDEIRO, D. L.; MARQUES, D. D. C.; OLIVEIRA, L. B.; CORREAA JUNIOR, M. B.; MACHADO, R. L.; SANTOS, R. N. S. Cáries e dentifrícios e o Ensino de Equilíbrio Químico. XV Encontro Nacional de Ensino de Química (XV ENEQ) - Brasília, DF, Brasil, p. 21-24, 2010.

GIGANTE, E. C.; GUIMARÃES, J. P. A Trajetória da saúde bucal pelas políticas públicas no Brasil a partir da criação do SUS. Caderno Saúde e Desenvolvimento. v.3, n. 2, P. 66-77, 2013.

GUEDES, C. C.; ALDRIQUI, J. M.; MARTINS, M. D.; FERNANDES, K. S. P; BUSSADORI, S. K. Remoção química e mecânica de lesão de cárie de dente 
hipoplásico utilizando-se gel à base de papaína Papacárie: relato de caso clínico.

ConScientiae Saúde, São Paulo. v. 5, p. 59-65, 2006.

JUNIOR, M. J.; VARANDA, L. C. O mundo dos colóides. Química Nova Na Escola. n. 9 , p. 9-13, 1999.

LIMA, J. E. O. Cárie dentária: um novo conceito. Revista Dental Press Ortodon Ortop Facial. v. 12, n. 6, p. 119-130, 2007. Disponível em:

<http://www.scielo.br/pdf/dpress/v12n6/a12v12n6.pdf > . Acessado em: 16/05/2016.

MARINHO, J. C. B.; SILVA, J. A. Conceituação da Educação em Saúde e suas implicações nas práticas escolares. Ensino, Saúde e Ambiente. v. 6, n. 3, p. 21-38, 2013.

MIALHE, F. L.; SILVA, C. M. C. A educação em saúde e suas representações entre alunos de um curso de odontologia. Ciência \& Saúde Coletiva. v. 16, n. 1, p. 1555 1561, 2011.

MOREIRA, M. A. Aprendizagem significativa: a teoria e textos complementares. São Paulo: Editora da Física, 2011.

NEVES, J. L. Pesquisa Qualitativa - Características, usos e possibilidades. Caderno de Pesquisas em Administração. São Paulo, v.1, n. 3, 1996. Disponível em:

$<$ http://www.unisc.br/portal/upload/com_arquivo/pesquisa_qualitativa_caracteristicas_u sos_e_possibilidades.pdf $>$. Acessado em: 16/05/2016.

PACHECO, S.M.V.; DAMASIO, F. Mapas conceituais e diagramas V: ferramentas para o ensino, a aprendizagem e a avaliação no ensino técnico. Ciências \& Cognição. v. 14, n. 2, p. 166-193, 2009.

RAUPP, F. M.; BEUREN, I. M. Metodologia da pesquisa aplicável às Ciências Sociais. Em BEUREN, I. M. (Org.). Como elaborar trabalhos monográficos em contabilidade: teoria e prática. 3 ed. São Paulo: Atlas, 2006.

SALIBA, N. A.; MOIMAZ, S. A. S.; SALIBA, O.; TIANO, A. V. P. Perda dentária em uma população rural e as metas estabelecidas pela Organização Mundial de Saúde.

Ciência \& Saúde Coletiva. v. 15, n. 1, p. 1857-1864, 2010.

SANTOS-DAROZ, C. B.; DAROZ, L. G. D.; BATITUCCI, M. H. G.; BATITUCCI, E.; MIRANDA, M. S. Classificação e tratamento de lesões dentárias não cariosas por estudantes de Odontologia. Revista Brasileira de Pesquisa em Saúde. v. 9, n. 1, p. 5$12,2007$.

SILVA, R. R.; FERREIRA, G. A. L.; BAPTISTA, J. A.; DINIZ, F. V. A química e a conservação de dentes. Química Nova na Escola. n. 13, p. 3-8, 2001.

SILVEIRA, D. T.; CÓRDOVA, F. P. A Pesquisa científica. Em GERHARDT, T. E.; SILVEIRA, D. T.(orgs). Métodos de Pesquisa. Porto Alegre: Editora da UFRGS, 2009.

SOSSAI, N.; VERDINELLI, E. C.; BASSEGIO, W. Clareamento dental. Revista Saúde e Pesquisa. v. 4, n. 3, p. 425-436, 2011. 
SOUZA, J. J. N. Experimentação no Ensino Noturno: uma proposta para o Ensino de Química. Dissertação de mestrado apresentada no Mestrado Profissional em Ensino de Ciências, Universidade de Brasília, Brasília, DF, 2013.

TANAKA, C. Análise do conteúdo sobre saúde bucal no material didático de Ciências de $1^{a}$ a $4^{a}$ série de escolas de Ensino Fundamental de Araçatuba - SP. Dissertação apresentada ao Programa de Pós-Graduação em Odontologia Preventiva e Social da Faculdade de Odontologia de Araçatuba, Universidade Estadual Paulista Júlio de Mesquita Filho, 2006, 78 páginas Disponível em:

〈http://www.foa.unesp.br/include/arquivos/foa/files/CLAUDIO_TANAKA.pdf $>$. Acessado em: 10/06/2016.

VASUDEVAN, D. M.; SREEKUMARI; S.; VAYDIANATHAN, K. Text book of biochemistry for dental students. 2. ed., London: Jypee Brothers Medical Publishers (P) LTD, 2011. 